Comparative Philosophy Volume 6, No. 2 (2015): 35-57

Open Access / ISSN 2151-6014

www.comparativephilosophy.org

\title{
PUBLIC PHILOSOPHY: CROSS-CULTURAL AND MULTI-DISCIPLINARY
}

\author{
ANAND JAYPRAKASH VAIDYA
}

\begin{abstract}
In this paper I propose a future direction for comparative philosophy on which it enters the space of public philosophy by capitalizing on the fact that it is already cross-cultural, and adding multi-disciplinary research to its proper foundation. This is not a new thesis. Rather, it is an ideological articulation of thought that is already underway in what is sometimes called fusion philosophy, as found in the work of Evan Thompson, Jay Garfield, or Christian Coseru. My articulation begins with a non-exhaustive delineation of distinct types of public-philosophy that are already well known in the public space. One core distinction I draw concerns how the very notion of 'public philosophy' can be understood. I distinguish between the philosophy-to-public direction of fit, on which philosophers enter the public space for some public benefit, and the public-to-philosophy direction of fit, on which the public plays a constructive role in guiding philosophers in some important epistemic manner. Because my position engages the issue of whether "philosophy" can truly be found outside of the west, I offer an account of the relation between science, religion, and philosophy with respect to inquiry into the human condition. In doing so I offer an argument against the view that philosophy can only be found in the west based on the difference between a term in a language and what the term picks out. I close with a discussion of how analytic philosophy, comparative philosophy, and experimental philosophy can come together to form one kind of bidirectional public philosophy.
\end{abstract}

Keywords: public philosophy, experimental philosophy, comparative philosophy, Gettier counterexamples, the demarcation problem, the problem of inclusion

\section{A NEW DIRECTION FOR COMPARATIVE PHILOSOPHY}

The discipline of comparative philosophy has a deep history that is both theoretically and politically problematic. It is theoretically problematic because the very idea of comparative philosophy faces the coherence problem. How is it possible for one to compare two distinct traditions of thought about the world? If they are distinct, how can they be meaningfully compared? It is politically problematic because it faces the

VAIDYA, Anand J.: Associate Professor of Philosophy, San Jose State University, USA. Email: anand.vaidya@sjsu.edu 
ranking presumption. How is it that distinct traditions of thought on a topic, say justice, can be compared without an implicit ranking of those traditions being made? If distinct traditions offer an answer to the same question, how is it that in comparing what those traditions say about the topic one does not already engage in an evaluation (either implicit or explicit) of which tradition offered a better answer?

One important moment in the recent history of comparative philosophy was, and continues to be, the development of the constructive-engagement approach to comparative philosophy, which deals with some of the important theoretical issues that critics of comparative philosophy have waged against it, such as the coherence problem. Bo Mou is the key pioneer of this important movement, and in his many works he outlines what the constructive-engagement strategy is, how it should be done, and why it is important. One significant explanation of the strategy is presented in his (2010) piece, "On the Constructive-Engagement Strategy of Comparative Philosophy" in the founding edition of this journal.

In what follows I would like to develop a new direction for comparative philosophy. I believe that this new direction already exits in intellectual space, but it simply has not been captured as a structured ideology or way of thinking about comparative philosophy. The new direction builds off of the constructive engagement methodology that Bo Mou has carefully articulated. The direction has as its fundamental aim to push comparative philosophy outside of the purely academic space and into the space of public philosophy. While the academic component of comparative philosophy, especially constructive engagement, is a necessary condition for its proper functioning and development, I argue that moving in the direction of public philosophy is beneficial for comparative philosophy, public philosophy, and the revitalization of the discipline of philosophy itself. My reason for suggesting this directional shift is that comparative philosophy, understood in a specific way, offers public philosophy a lens through which it can be part of the non-academic space of intellectual engagement in a way that is relevant to our current time period in which global citizenship is increasingly important. In addition, comparative philosophy can serve as a means for ameliorating the diversity inclusion problem for philosophy. In what follows I begin with a non-exhaustive delineation of different kinds of public philosophy. From there I move into a series of issues relating to the possibility of including non-western traditions into philosophy and the practical problem of making philosophy more inclusive. I close with a discussion of how cross-cultural and multidisciplinary philosophy is a kind of public philosophy.

\section{VARIETIES OF PUBLIC PHILOSOPHY}

What is public philosophy? We can distinguish between at least two distinct ways of unpacking the phrase. On the philosophy-to-public direction of fit, public philosophy is about trained academic philosophers engaging in philosophy that is (i) somehow more in the public space than merely in the academic space, and (ii) for the benefit of the public, but not necessarily for the benefit of the academic discipline. On the public-to-philosophy direction of fit, public philosophy is about the non- 
philosophically trained public (academic or not) engaging in philosophy that is (iii) in the public space, and (iv) for the benefit of all. Because we can distinguish between these two directions of fit, we can also say that there are unidirectional instances of public philosophy, that is, kinds that go only in one direction, and that there are bidirectional instances of public philosophy, that is, kinds that mix both directions. In my view, less attention has been given to the public-to-philosophy direction of fit, and to bidirectional public philosophy. Nevertheless, I begin by delineating several kinds of public philosophy that fit under the former direction of fit.

There are many different subtypes of public philosophy that fit under the philosophy-to-public direction of fit.

Social Analysis philosophy aims to draw philosophy into the public sphere through engagement with topics of social concern, such as gay marriage, privacy, gun control, the death penalty, or animal rights. An analysis is typically done by using some component of classical moral, social, and political philosophy in conjunction with an engagement with legal or economic theory. Philosophers working on this kind of public philosophy typically take theories, such as Utilitarianism, Kantianism, Virtue Ethics, Rawlsian Distributive Justice, Nozickian Entitlement Theory, or Sen's Capabilities Approach, and analyze a social phenomenon. This kind of public philosophy is the one that rings most commonly in the minds of both academic philosophers and the public when they hear the phrase 'public philosophy'. The core idea is that the kind of philosophy done is 'public' because it is concerned with social issues. A key example of this kind of public philosophy can be found in the work of Michael Sandel's Justice: What is the Right Thing to Do? Or his earlier work: Public Philosophy. But it can also be found in the work of Peter Singer's The Ethics of What We Eat: Why Our Food Choices Matter.

Activist philosophy is closely related to social analysis philosophy. The difference between the two is that social analysis aims to offer an analysis of a problem in the social sphere that theoretically illuminates it, while activist philosophy aims to call out for action through a revealing analysis of a phenomenon. Angela Davis's, Are Prisons Obsolete? And Vandana Shiva's Water Wars: Privatization, Pollution, and Profit are two good examples of this kind of work. While philosophers working on social analysis lean more toward offering an engaging analysis about why, for example, gun control is required and gay marriage is morally permissible, activist philosophers lean more toward drawing out awareness in a way that is an explicit call to action.

In contrast to the social and activist styles of public philosophy, enrichment philosophy aims to enrich the public's understanding of a phenomenon in the human condition, such as the nature of death, anxiety, the self, rationality, or freedom. It aims to do this in part by deleting high-level and obfuscating vocabulary found in academic philosophy, and replacing it with engaging descriptions and examples, often taken from pop culture. We are brought in for a kind of enrichment through poised reflection on a component of our shared world. The New York Times column The Stone contains many articles of this kind. For example, Timothy Williamson's Logic and Neutrality is a wonderful short piece that enriches the public's understanding of 
the fundamental nature of logic in an accessible way, and Benjamin Bratton's Outing A.I.: Beyond the Turing Test nicely gives the public a critical insight into the current rebirth of research in artificial intelligence. Importantly, while enrichment philosophy may use historical figures, such as Spinoza or Kant, or contemporary figures, such as Linda Alcoff, Naomi Zack, or Martha Nussbaum, it need not. What is central is that the philosopher brings to the public's attention some insight about the human condition through an analysis of a phenomenon. Unlike social analysis style public philosophy, which aims to capture and investigate social phenomenon already in the popular imagination, the topic in enrichment style public philosophy may not be something the public is knowledgeable about or concerned with.

Journalistic philosophy as a kind of public philosophy, like its counterpart in science journalism, aims to inform the public about the thoughts of philosophers on various topics. The central aim is to disclose what Plato, Aristotle, Seneca, Descartes, Spinoza, or Kant thought about the nature of virtues, the mind, or knowledge? Journalistic philosophy need not aim to offer any insight into the topic at hand other than what is offered by the philosopher who is the subject. More importantly, it serves as an introduction for the public to a figure or a topic. Richard Marshall of 3. A.M. Magazine, for example, does interviews with contemporary philosophers, such as Pamela Heironymi, in which their work is surveyed, and the public gets to know what a contemporary thinker in the profession is like and what they work on. Although these are distinct ways of engaging in the philosophy-to-public direction of fit, by no means is it ruled out that these activities can be combined. Many of the radio programs in philosophy, such as those done by Stanford's Philosophy Talk, run by John Perry and Ken Taylor, and Philosophy Bites, run by David Edmonds and Nigel Warburton, mix elements from all categories. In addition, magazines, such as Philosophy Now or New Philosopher's Magazine also engage in a wide mixture, blending the different kinds of philosophy found under the public-to-philosophy direction of fit.

Importantly, though, most public philosophy of the first kind simply does not engage a lot of non-western thinkers. This doesn't mean that there are no instances. For example, Edmonds and Warburton have a wonderful interview with Alison Gopnik on the possible influence of Buddhism on Hume. George Yancy has a series of interviews in The Stone in which he discusses issues surrounding race with a wide variety of contemporary philosophers, such as his interview on Afrocentricity with Molefi Kete. In addition, there is a wonderful piece in Aeon magazine in which Graham Priest discusses the nature of Buddhist logic. However, for the most part, figures from outside of the western canon are under represented. We don't see a lot of journalistic philosophy about figures, such as Udayana Nāgārjuna, Ibn Sina, or Confucius. We don't see a lot of contemporary philosophers from outside the main leading universities in the West, and we don't see a lot of discussion of topics presented, either in the New York Times or elsewhere, from a comparative point of view that includes cross-cultural and multi-disciplinary perspectives.

In contrast to this direction of fit, the public-to-philosophy direction of fit is a quite different enterprise, one that is often not even noticed as a reading of "public 
philosophy'. For it begins with the idea that there is a non-academic way of doing philosophy that is worldly, and it assumes that philosophy as a discipline could require directional navigation from the public. Moreover, it challenges the idea that philosophy is always theoretically prepared for the purposes of analyzing and explaining components of the human condition. This direction recognizes that for philosophy to evolve in a relevant and meaningful way over time it must not only be prepared to analyze for, but also to attend to. That is, the philosopher needs to not only be skilled at analyzing what is present in the world, but also at listening to and hearing what is going on in the world. It is the sensitivity of an appropriately cultivated ear and the eye, and not solely the mind that drives public philosophy of this kind. A philosopher of this sort is a kind of investigative journalist, but the direction is from the public space to the academic space. The aim is to bring attention to that which is present in the world and in need of engagement, but has so far escaped philosophical attention.

With these two distinct directions in mind, I will argue that comparative philosophy that is both cross-cultural and multi-disciplinary is an important kind of bidirectional public philosophy because it mixes elements from the public-tophilosophy direction of fit with elements from the philosophy-to-public direction of fit. In addition, it has the potential to make philosophy that is strictly outside of the social and political sphere more attractive and engaging to the public. However, before one can even argue for the possibility of comparative philosophy as public philosophy, one must make the case for the claim that there can even be philosophy outside of the western tradition tracing back to Plato. To make the case that there is philosophy to be found outside of the west, let me turn to a central problem in the philosophy of philosophy, which is also found in the philosophy of science: the demarcation problem.

\section{THE DEMARCATION PROBLEM FOR PHILOSOPHY}

No one would ever argue as follows: 'Water' is a term that belongs to the English language, so there is no water in India, China, Africa, or Iran. Clearly, it could be the case that what 'water' picks out can still be found in any of those places, even if 'water' is not to be found in Sanskrit, Mandarin, Swahili, or Persian. Any one who makes a distinction between a word and what the word picks out, is in a position to understand this point. So, what is the difference between 'philosophy' and 'water'? For it is not uncommon for one to encounter an argument that basically runs as follows. Since 'philosophy' was introduced to the world at a specific time period in Greece, against a specific political backdrop, and with a specific purpose, what 'philosophy' picks out cannot be found in India, China, Africa, or Iran. Another way in which the point can be made is by noting the fact that while philosophy is, supposedly, separate from religion in the West, it is claimed not to be so outside of the West. And importantly, in the $20^{\text {th }}$ century there is supposed to be a strong separation between philosophy and religion in the west, while in non-western thought, there arguably is no such strong separation. Yet another way of bringing out the 
problem is by noting that there are two ways in which philosophy can be picked out: by method or by topics. The overall argument runs as follows:

1. Either 'philosophy' refers to a method, a set of topics, or a set of topics and a method.

2. Outside of the western canon one cannot find either the same topics, or the same method as that which is found in the western canon.

3. Only if one can find the same topics or the same method can one claim that something outside of the western canon counts as philosophy.

$\therefore$

4. There is no philosophy outside of the western canon.

Lets assume for a moment that (1) is true, and that for the most part there are only two ways to pick out what 'philosophy' refers to, either via topics, such as truth, beauty, justice, and causation, or via methods, such as the method of case analysis that utilizes intuitions about cases or through hypothesis testing via experimentation. With this background in place, let's examine some problems with (2) and (3).

Take the topics account first. On the topics account of philosophy, there is some fixed set of topics that count as being philosophical, which cannot be altered, call that set $\mathrm{T}$. Then the argument would hold that no other culture or tradition has inquired into all of the elements of $\mathrm{T}$. Now it might be true that no culture or tradition has inquired into all of the elements of $\mathrm{T}$, but it is impossible to argue that most cultures have not inquired into at least some elements of T. For example, although Ancient Indian pramanna debates are not exactly the same thing as Ancient Greek epistemology or Anglo-Analytic epistemology, it would be hard to argue that there is no common concern for how humans acquire knowledge that the two traditions share. Likewise, it would be too easy to point out that there are differences between Confucian virtue ethics and Aristotelian virtue ethics. It is much harder to lay claim to the position that Confucius and Aristotle were not both concerned with the role that virtues play in living the good life. So, the topics approach for holding that there is no philosophy outside of the western canon simply fails. Because just as we find the substance picked out by 'water' in different geographical regions around the world, even when it is referred to by different words, such as, 'wasser' in German vs. 'paani' in Hindi, we find that questions concerning the nature of perception, ethics, and justice are found in different cultures, even though different words are used, such as, 'epistemology' in the Anglo-philosophical world vs. 'pramāna' in the ancient Indian world. What about the methods approach?

The methods approach suffers from a problem internal to the western canon that makes it unlikely to hold any weight in pushing aside philosophical insight by those who are not members of the western canon. The main problem is the continuity of method problem. Assume that there is some method $\mathrm{M}$, which is part of the western canon of philosophy at its birth, for example, the method of case analysis involving intuition. Is it possible to argue that no member of the western canon actually disputed $\mathrm{M}$ and also counted as a philosopher? Unlikely, since one need only point to 
the difference between rationalists and empiricists, or between, more recently, experimental philosophers and armchair philosophers, to note that there are big differences over what constitutes good philosophical methodology. Another way to put the point is that the non-continuity of a single methodology for doing philosophy over time is simply a function of the fact that 'philosophy' is not a classical concept, with a fixed set of necessary and sufficient conditions that includes a single methodology. Rather, it is a family resemblance concept involving a pattern of similarity and dissimilarity tracing down through lines of inheritance in one way or another back to a root. If the continuity problem holds, then one is in a position to point out that those outside of the western tradition may have engaged a topic in a way that is similar to how one group of philosophers in the west engaged a topic at one time, but not at another time. For example, we may find, as Jonardon Ganeri points out, that in India from 1450-1700, Indian thinkers engage a methodology that is strikingly rationalist in nature. ${ }^{1}$ One could argue that in this period thinkers asking questions about the human condition, asked by philosophers in the western canon, use a method similar to that of their western peers at one time, but dissimilar from their western peers at a different time.

Thus, one should not hold that thought about the human condition from outside of the western canon does not count as philosophy simply by pointing to the fact that 'philosophy' is connected to either a set of topics or a method, neither of which is found outside of the west. Continuing the analogy with 'water' we should take note of the fact that there are qualified uses of 'water', such as 'heavy water' and 'hard water' where the substance picked out by the qualified notion bears a resemblance relation to $\mathrm{H}_{2} \mathrm{O}$. The qualification is in play because it captures an interest relative joint in nature. Moreover, a correct use of 'water' is consistent with the fact that the substance picked out on the occasion of use may not be pure $\mathrm{H}_{2} \mathrm{O}$, for even a pure sample of water does not contain pure $\mathrm{H}_{2} \mathrm{O}$. This train of thought should open our minds to the fact that a use of 'water' maybe strongly connected to what a person does with water. Many of us use 'water' as a term for the substance that we can and would drink or take a shower in. And what "we", non-scientists, think about what water is, could be very different from what scientists studying water associate with 'water'. My suggestion here is that what we are willing to accept as an account of 'water' also works with 'philosophy', even though the former is a natural kind (a substance whose existence does not depend on human consciousness), and the latter is a social kind (a phenomenon or entity whose existence depends on the engagement between humans). Thus, outside of the west we might not find the exact referent of 'philosophy' as found in the west, but we might find something called religious philosophy or scientific philosophy, just as we might find heavy water and hard water in some geographical regions. There is no reason to think that traditions that cannot lay claim to the word 'philosophy' are not thinking about questions in and of the human condition in an important way that should be engaged by those that can lay claim, through traditional means, to the term 'philosophy'.

\footnotetext{
${ }^{1}$ See J. Ganeri's Lost Age of Reason for a robust discussion of this issue.
} 
Taking note of this point, we can approach the demarcation problem for philosophy by drawing out the relation that philosophy could bear to two other areas of inquiry into the human condition, science and religion. The guiding question is: how can we properly demarcate philosophy from science and religion? The static approach maintains that there is an exact set of necessary and sufficient conditions for solving the demarcation problem for philosophy. The floating approach maintains that there are features of philosophy that allow it to float between a more or less religious outlook and a more or less scientific outlook. On this approach what falls under 'philosophy' lies on a continuum, on the one hand being closely connected to religious thought, on the other hand being closely connected to scientific thought. This model of philosophy can best be described by three triangles.

Where ' $P$ ' stands for philosophy, ' $R$ ' stands for religion, and ' $S$ ' stands for science, consider the following, left-to-right progression.

Philosophy-to-Science — philosophy looks more like scientific inquiry

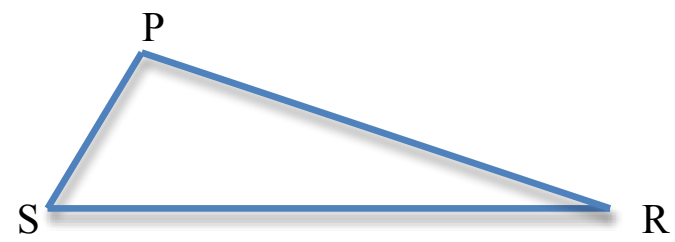

Philosophy-in-balance-with Science and Religion-philosophy is neither

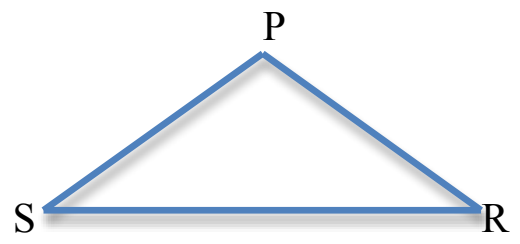

Philosophy-to-Religion — philosophy looks more like religious inquiry

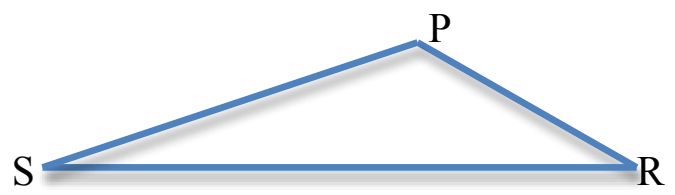

In general, the triangles should be read as marking certain specific points on a progression. Leaning left philosophy is more scientific. Leaning right it is more religious. Approaching center it is in balance. In addition, there are two ways one can read the triangles. On the one hand, the triangles can be read as being about whole traditions of inquiry. For example: What does British Empiricism look like? What does Abhidharma Buddhism look like? On the other hand, the triangles can be read as being about particular topics of inquiry as investigated by specific figures. For 
example: According to Confucius, what is the good life? According to Sen, what is the nature of justice? The general idea is that we go in for the view that questions in or about the human condition can be examined from either a scientific, philosophical, or religious standpoint. And while we may have strong cross-cultural intuitions about what demarcates science from religion, we may not have as strong intuitions about where philosophical inquiry falls. So, we adopt a gradient progression view captured by the shifting top point of a triangle.

Finally, the demarcation problem for philosophy is not just a theoretical problem about detection. It is also a political problem that effects how philosophy is taught around the world. And it is perhaps to this issue that one must eventually turn when addressing the issue of how philosophy can be more inclusive.

\section{TWO KINDS OF INCLUSION: ROOM FOR MORE DISCUSSION}

Today many philosophers are worried about the demographics of philosophy. We hear worries about the fact that: (i) there are not a lot of women in philosophy, (ii) there are not a lot of ethnic and racial minorities in philosophy, (iii) there are not a lot of people with cognitive and / or physical disabilities in philosophy, and (iv) philosophy is heteronormative. More importantly, though, we hear a general complaint: the climate of philosophy is hostile towards the inclusion of women, minorities, and persons with disabilities, and it promotes a heteronormative worldview. The hostility complaint is important because were there no hostility towards inclusion we might rightly wonder: why are there so few women, minorities, persons with disabilities, and non-heterosexual members in the discipline? And whatever answer we find, it would likely allow for the discipline being excused, because the non-representativeness could not be traced back to an intention on the part of philosophers to actively exclude or passively non-include women, minorities, persons with disabilities, or non-heterosexuals. So, we face the inclusion problem: given the hostile environment, how do we fix the lack of representation? We can distinguish between two different approaches to solving the problem.

The diffusion of hostility approach focuses on the hostility and not the content of philosophy. The idea is that philosophy can become more inclusive by simply dropping the hostile attitude, changing to a better attitude, but ultimately leaving all the content the same. On this approach the canon does not, and maybe even should not be changed. Analytic metaphysics, Heidegger, formal epistemology, mathematical logic, meta-ethics, and the history series from Plato to Kant are all perfectly good components for a philosophical education. Rather than changing the content, the attitudes of those in the discipline need to change, and educational methods need to be improved in order to transmit the present content to the relevant populations so as to get a more diverse group of people into philosophy as it presently is. But, as the story goes, we don't need to change the curriculum that much. Some might even go so far as to say that the curriculum, as it is, is good because it focuses on the well-known intellectual commodity of analytic thinking, which many other professions, such as the legal profession, seek. So, if you can't get a job in philosophy, 
you can at least use the analytical thinking skills you gain to get a job.

The diffusion of hostility and canon alteration approach focuses on the hostility also - because that simply has to go- but it goes further into the canon, arguing that it must be changed as well. For example, it aims to include the work of women from a number of historical periods, such as the early and late Modern period, where we find, Mary Astell and Sophie De Grouchy. It also aims to promote the importance of the work of women in the $20^{\text {th }}$ century, such as Elizabeth Anscombe, Ruth Marcus, or Philippa Foot, as well as provide more opportunities for women to grow in philosophy, such as through the Mathematical Philosophy for Female Students Summer School at the Munich Institute for Mathematical Philosophy. Correcting on the gender axis it hopes to gain greater participation in philosophy from women through reducing the hostility towards women, on the one hand, but also by showing young women, and men, that the canon neglects a vast array of important contributions by women. This approach appears to be a necessary part of any change that philosophy should aim to correct for.

A distinct problem for inclusion in philosophy comes when one wants to move past the diffusion of hostility, beyond the inclusion of women, and on to the problematic terrain of extending outward to distinct traditions that cannot lay claim to being philosophical because the tradition is not backward traceable to Plato. Rather, these traditions fall somewhere on the gradation of triangles from leaning left to leaning right. For example, in this area we face the question: Should we include Aztec, Latin American, Africana, African American, Indian, Chinese, and Arabic thought to the standard philosophy curriculum? And this question cannot be answered without also considering how it would be properly implemented? For example, should we be teaching separate courses on Latin American philosophy and Indian philosophy? Or should we just broaden the definition of Ancient philosophy so that one can teach, in addition to the metaphysics of Heraclitus and Parmenides, the metaphysics of Advaita Vedānta and Nahuatl?

In addition, when we look to answer both questions, we have to keep in mind the background issue. It is not as if one cannot go to college and learn about metaphysical ideas that are outside of the western canon. It might just be that in order to do that one needs to step into an Asian Studies Department or a Latin American Studies department in addition to a philosophy department. The extension is driven by the idea that the representativeness of philosophy will improve by including these ideas. Simply put, by talking about the ideas of African American, Latin American, and Chinese philosophers, for example, we give members of these groups what, for lack of a better term, could be called a positive identity trajectory into philosophy. And that claim is controversial. It is not clear that talking about the ideas of people from these areas gives members from these areas any more reason to want to get into philosophy than simply showing them the importance of mathematical logic, scientific inquiry, or analytic political philosophy and metaphysics. Inclusion of this kind aims to point to the fact that questions in and of the human condition have been explored by every culture, and the culture to which a person belongs should be shown, where possible, to be an important participant in a larger conversation. It is with this 
part of the answer that we also find another valuable component of extending out to other cultures that goes beyond membership inclusion.

Putting aside membership, the extension allows for the dominant group to be better informed, for we need not conceive of the benefit of changing the canon so as to include non-western thinkers as being only of other directed instrumental value. That is, as a means to a more representative body of philosophers. We can also conceive of it as a necessity because it improves the education of the dominant membership already. That is, regardless of whether philosophy can ever change so as to be more representative of the vast diversity of people there are, there is an imperative that maintains that the canon should change for the purposes of allowing for a better education for the current members of the philosophical community. Why should we produce more philosophers that are simply ignorant of other cultures and traditions? Isn't it to the advantage of the members of the current dominant group to be better educated by being aware of ideas from other cultures? The advantage lies in one's ability to write new philosophy that is fresh. Perhaps the best way to see this advantage is to turn to places where important and valuable changes in philosophy have been brought about by engaging other areas of inquiry that are not cross-cultural. Rather, they cut across disciplines.

\section{OF MATH AND SCIENCE: MORE TOOLS, NOT NECESSARILY BETTER TOOLS}

Although mathematics has always been a central and important part of philosophy since Plato's time, there is a distinctive way in which the use of mathematical and logical methods changed philosophy in the beginning of the $20^{\text {th }}$ century. No deep history of analytic philosophy is required for one to grasp the importance of logic and mathematics to the future trajectory of philosophy as Frege, Russell, and Wittgenstein shaped it, for the change they instigated does not lie simply in pointing to language when thinking about philosophical problems. It lies in the way in which they went about analyzing language to solve philosophical problems. A single example could never suffice evidentially to prove this claim, but it will be instructive for what is at hand.

Russell's analysis of definite descriptions is a decisive moment in the trajectory that analytic philosophy underwent. At least one thing that was contributed to philosophy in that moment was not simply the use of logic and mathematics, but rather the idea that logic and mathematics could be used to improve the set of tools that philosophers had available for dealing with philosophical problems. The core question Russell was dealing with is: How can we make sense of certain sentences in a way that allows us not to be committed to the existence of strange objects, such as subsistent yet non-existent individuals? That is, how do we make sense of

(i) 'The present king of France is bald'

when another sentence, 
(ii) 'The present king of France does not exist'

is true?

One simple answer is to say that a sentence, such as (i), has no truth-value, since a sentence of that kind is true when the entity picked out by the subject term has the property attributed to it by the predicate term, and in fact 'The present king of France' does not pick anything out, since, when Russell was writing, France was no longer a monarchy. But this solution makes many nervous since a consequence of it is that we also have to say that there are counterexamples to the Law of Excluded Middle, LEM, which states that every sentence is either true or false. If (i) has no truth-value, then (i) is a counterexample to LEM. Russell, brilliantly, offers us a way of preserving LEM, while also making sense of (i). His solution is roughly the following:

Using:

(iii) ' $K x$ ' as an abbreviation for ' $x$ is a present king of France', and ' $B x$ ' as an abbreviation for ' $x$ is bald'.

Analyze:

(i) The present king of France is bald.

as a conjunction with an existential quantifier in wide scope:

$$
\exists x[K x \wedge(\forall y(K y \rightarrow(y=x)) \wedge B x)]
$$

Now, given that

(ii) The present king of France does not exist.

it follows that (iv) is false, since there is an existential quantifier that is not satisfied.

That is, since there is nothing that satisfies 'there is something that is a present king of France' it follows that 'the present king of France is bald' is false, since a conjunction, the analysis of (i) as (iv), is false when one of its conjuncts is false. As a consequence, we don't get either the conclusion that LEM has counterexamples or the conclusion that there is some non-existent yet subsistent king of France that is bald.

My general point is simple. The tools of logic help us offer a kind of solution to the philosophical problem of what to say about the truth-value of sentences where the subject term has no reference. We need not commit ourselves further to the claim that Russell's solution is correct or even the best on offer. The important point is that logic is an important tool that allowed for a kind of solution to come into play.

Keeping the foray into mathematical logic at the turn of the $20^{\text {th }}$ century in mind, I want to turn attention to a more recent example, that bears further consideration: 
experimental philosophy, which aims to improve philosophy by using methods found in the social sciences, as opposed to mathematical logic. There are various kinds of experimental philosophy. For my purposes here I will be focusing on one important strand that allows us to see how reaching out of philosophy to other disciplines, such as the social sciences, can take us back to cross-cultural philosophy.

One of the most important moments in $20^{\text {th }}$ century analytic philosophy is Gettier's (1963) notorious defense of the claim that Plato's tripartite analysis of knowledge is false. The tripartite analysis of knowledge holds that knowledge is equivalent to justified true belief, since knowledge cannot be accidental, and true belief alone can be accidental. For example, think of the difference between guessing and knowing. The background of Gettier's work requires the following four claims.

(i) $[\mathrm{K} p \equiv \mathrm{JTB} p] \quad$ Knowledge is equivalent to justified true belief.

(ii) $[\mathrm{JTB} p \rightarrow \mathrm{K} p] \quad$ If one has justified true belief, then one knows.

(iii) $\neg(\mathrm{J} p \rightarrow p) \quad$ Justification is fallible.

(iv) $\mathrm{J} p, \mathrm{~J}(p \rightarrow q) / \mathrm{J} q \quad$ Justification is closed under deduction.

With (i)-(iv) in place Gettier goes on to produce two counterexamples to (ii), one of which is roughly the following. Suppose:

(a) Jones gets a ride to work in a Ford from Smith. Jones asks Smith, "Do you own this Ford?" Smith responds by showing an ownership slip with his name on it.

(b) On the basis of the ownership slip, Jones forms the justified belief that $p=$ Smith owns a Ford.

(c) Later at work Jones, noticing the absence of Brown from his desk, considers whether Brown is in Barcelona, perhaps on vacation. He decides, on the basis of no evidence, that $q=$ Brown is in Barcelona.

(d) He now forms the disjunctive proposition $(p \vee q)$ on the basis of his justified belief that $p$. That is, using the closure of justification he argues that if $p$ is true, then either $p$ or $q$ is true. And since he is justified in believing that $p$, he is justified in believing either $p$ or $q$.

(e) However, unbeknownst to Jones, Smith does not own the Ford, the ownership slip has the name of another Smith on it; but Brown happens to be in Barcelona, having scheduled a trip earlier in the month.

With (a)-(e) in place, the question is: Does Jones know that either Smith owns a Ford or Brown is in Barcelona?

According to many philosophers there is simply no way that Jones knows the disjunction. However, and controversially, according to some experimental philosophers, Weinberg, Nichols, and Stich (2001), there is cross-cultural surveybased evidence that suggests that east Asians, especially those who can trace their decent to the subcontinent of India, Pakistan, and Bangladesh, do not share the intuition that a person in a Gettier situation, such as Jones, lacks knowledge, and simply only believes. 
The story that Weinberg, Nichols, and Stitch use to explore whether there are cultural differences on Gettier cases was the following:

Bob has a friend, Jill, who has driven a Buick for many years. Bob therefore thinks that Jill drives an American car. He is not aware, however, that her Buick has recently been stolen, and he is also not aware that Jill has replaced it with a Pontiac, which is a different kind of American car. Does Bob really know that Jill drives an American car, or does he only believe it?

\section{REALLY KNOWS}

ONLY BELIEVES

After collecting data on the responses of east Asians, they went on to test a further subgroup of east Asians, and noted the following results.

The experiments we have reported thus far were done in lower division classes and large lectures at Rutgers. Since Rutgers is the State University of New Jersey and New Jersey is home to many people of Indian, Pakistani and Bangladeshi descent, in the course of the experiments we collected lots of data about these people's intuitions. Initially we simply set these data aside since we had no theoretical basis for expecting that the epistemic intuitions of people from the Indian sub-continent (hereafter SCs) would be systematically different from the epistemic intuitions of Westerners. But, after finding the extraordinary differences between Westerners and east Asians on the Gettier case, we thought it might be interesting to analyze the SC data as well. We were right. It turns out that the epistemic intuitions of SCs are even more different from the intuitions of Westerners than the intuitions of east Asians are...If these results are robust, then it seems that what counts as knowledge on the banks of the Ganges does not count as knowledge on the banks of the Mississippi! (Weinberg, Nichols, and Stitch 2001: section 3.3.3, emphasis added)

Simply put, they argue that westerners and those of Indian, Pakistani, or Bangladeshi decent do not share the same intuition about Gettier cases. ${ }^{2}$

Now, one way to look at this kind of work in experimental philosophy is through the lens of tool enhancement. The idea is that we can simply improve the way we do philosophy by reaching out to other disciplines, such as cross-cultural psychology, anthropology, or neuroscience, just as we can improve philosophy by reaching out to mathematical logic. We gain insight into the nature of knowledge by looking at potential cross-cultural variations in folk judgments about knowledge.

Keeping in mind the tool enhancement view of experimental philosophy, I want to consider the following question: how might the tools provided by experimental

\footnotetext{
2 It is important to note that there is a controversy over whether the initial study in fact holds. That is, there is a controversy over whether there even is any cross-cultural variation between the two groups. Nagel, San Juan, and Mar (2013) show that a study of cross-cultural variation similar to that of Weinberg et al. (2001) failed to replicate. And more recently, Kim \& Yuan's, "No Cross-Cultural Differences in Gettier Car Intuition: A Replication Study of Weinberg et al. 2001," argue that the initial study does not replicate.
} 
philosophy, for example the survey methodology used above, be improved further by engaging historically informed comparative philosophy? Although the experimental study of Gettier intuitions is about variation in folk judgments about the attribution of knowledge in a Gettier scenario between Europeans and Indians, what are we supposed to think of the fact that there are deep epistemological investigations in classical Indian philosophy that can inform our analytical and empirical inquiry crossculturally? That is: why only look at folk intuitions? Why not also engage comparative philosophy to find theories and or examples for further cross-cultural investigation?

For example, let's consider the controversial claim that there are Gettier-style examples to be found in classical Indian philosophy. B. K. Matilal (1986) is at least one source for the claim; a counter argument is discussed by Potter (1984), and a critical and in depth engagement of how the Nyāya school of philosophy would engage the Gettier counterexample is offered by Shaw $(2015 a, b)$. Here is a pathway into the some of the issues.

One of the most important arguments in classical Indian philosophy is the FireSyllogism. The syllogism is presented and discussed by Gautama Akșapāda in his Nyāya-Sutras. It serves a role in classical Indian epistemology similar to that of Aristotle's example of a good deductive argument, which I here will refer to as the Mortality Syllogism.

The Mortality Syllogism

Major Premise: $\quad$ All men are mortal.

Minor Premise: $\quad$ Socrates is a man.

Conclusion: $\quad$ Socrates is mortal.

\section{The Fire-Syllogism}

Thesis: $\quad$ There is fire on the hill over there.

Reason: $\quad$ I see smoke above the hill over there.

Connection: Wherever there is smoke there is fire, just as one finds in a kitchen when they are cooking, but never on a lake.

Application: The case of smoke above the hill is just like the case of smoke and fire in a kitchen, and unlike the case of the lake.

Conclusion: There is fire on the hill over there.

To this argument, it is well known in classical Indian philosophy that there are epistemological considerations that can elucidate components of the argument. Jonathan Stoltz (2007) offers an important discussion of an example deriving from the Buddhist philosopher Dharmottara. 


\section{The Case of Swarming Flies}

There is a fire on which meat is being cooked. While the fire has not produced any smoke, the cooking meat has enticed a large number of flies to swarm above the fire. Some person, looking at this scene from a distance, but without perceiving the fire, glimpses the swarm of flies and forms the mistaken belief that it is smoke. As a result of believing that there is smoke he 'infers' that there is fire. His belief that there is fire is true, but because he deduces the existence of fire from the false belief that there is smoke, his cognition should not be regarded as a knowledge episode. (Stoltz 2007: 398).

Stoltz's characterization of Dharmottara's example is important to consider.

[The case above is a case of] $\left(\mathrm{FA}_{2}\right)$ factive assessment possessing incorrect evidence (log pa'i rgyu mtshan can gyi yid dpyod). In this case, the cognitive agent $\mathrm{S}$ takes himself to have evidence e, knows that $\mathrm{p}$ follows from $\mathrm{e}$, and thus judges that $\mathrm{p}$. Unfortunately, $\mathrm{S}$ is in error about his inferential basis e, for e is false; $p$, however, is true. Thus, we have a case where $\mathrm{S}$ has a true judgement that $\mathrm{p}$, and this judgement is derived from an inference-like activity. Because S's evidence is mistaken, however, we can reasonably conclude that he does not actually know that p. (Stoltz 2007: 398)

Stoltz goes on to argue that while there are superficial similarities between the example of factive assessment, above, and Gettier cases, the similarities do not reveal a true parallel. His basic argument is insightful and revealing.

Factive assessment is held to be a specific type of mental episode, whereas true belief is not. No one thinks that true belief is a particular type of mental state different from (mere) belief. Yes, some beliefs are true and others are false; but this distinction applies to the content of beliefs, and not to the mental state of belief. The second problem is that the justified true belief analysis of knowledge is quite remote from Indo-Tibetan epistemology, and so finding a parallel to 'justification' within this context is not straightforward. This problem is compounded by the fact that if we are to attribute theories of justification to IndoTibetan epistemologists, many of these theories will need to be externalist in nature. Externalists commonly eschew the justified true belief model of knowledge, however. (Stoltz 2007: 396)

After a careful analysis he concludes:

[W]hile these Tibetans do recognize the possibility of inferential knowledge [and] factive assessment based on false evidence $\left(\mathrm{FA}_{2}\right), \ldots$ there is no discussion at all in these Tibetan writers of Gettier scenarios in which judgements are formed through appeals to justifiably believed but false evidential bases. To put it more bluntly, examples of factive assessment in the Tibetan tradition provide no true parallels to the Gettier problem. (Stoltz 2007: 400, emphasis added) 
With respect to the example from Dharmottara in relation to Gettier cases, Stoltz appears to be pointing towards the following argument.

1. The person, $A$, who glimpses a swarm of flies in the distance has a belief that there is smoke in the distance on the basis of what is glimpsed.

2. In order for the swarming flies case to be a true Gettier case, Indo-Tibetan epistemology must conceive of the judgment/belief of there being smoke on the basis of glimpsing swarming flies as a case of justified false belief on the basis of misperception.

3. According to Indo-Tibetan epistemology, $A$ 's belief that there is smoke in the distance on the basis of glimpsing swarming flies is deemed not justified. Furthermore, since IndoTibetan epistemology does not go in for the justified true belief analysis of knowledge, it is difficult to see how they could think that the glimpsing of swarming flies allows one to have a justified belief that there is smoke in the distance. Moreover, whatever justification turns out to be in order for Gettier-style examples to be possible, it is not easy to find or locate that similar notion of justification in Indo-Tibetan epistemology. Thus, a crucial component required for classifying the swarming flies case as a Gettier case is missing.

$\therefore$

4. The case of swarming flies is not a Gettier scenario, a case in which one has a justified true belief that is not knowledge.

Importantly, Stoltz also recognizes the complexity of classical Indian philosophy with regard to this issue. For example, he takes note of Matilal's engagement on the issue with respect to Advaita Vedānta, which is arguably different from that of the Indo-Tibetan Buddhist tradition.

Matilal (1986: 136) provides an example very similar to [the case of swarming flies] given by the twelfth-century Indian Advaita scholar Śrīharsa, and comments 'Notice that the person acquires a justified true belief in this case, as does the subject in most Gettier examples'. We should not be overhasty and conclude that these examples support the conclusion that such a person has a justified belief. It is arguably the case that this example could be described in such a way as to confer justification to the resultant belief. Nevertheless, this is not how these examples are in fact described or employed in the Indian and Tibetan Buddhist context. Examples of this sort, including the well known case of a person mistaking a rope for a snake, are put forward as examples of mistaken beliefs, and it is never claimed by Indian or Tibetan writers that these mistaken beliefs should be considered epistemically justified. (Stoltz 2007: 399, emphasis added)

And in a very important comparative engagement across the Anglo-Analytic tradition and the Indo-Tibetan tradition Stoltz also notes the following:

Indian epistemology is notable for the great emphasis it places on detailing the legitimate means or instruments of knowledge (pramāna). Non-Buddhist philosophers draw a distinction between these means of knowledge and the mental event of knowing (pramā). Buddhist epistemologists, following the sixthcentury Indian epistemologist Dignāga, reject this distinction and maintain that 
the event of knowing is not different from its means or instrument. What is important in this context is that in the Indian Buddhist epistemological tradition pramā (knowing) is a mental event -a cognitive episode. In this way, Indian Buddhist accounts of pramā differ greatly from typical analytic accounts of knowledge, in which knowing is ordinarily not regarded as a mental event. (Stoltz 2007: 401)

He further clarifies this point by noting a difference between Buddhist schools and Hindu schools, such as Navya-Nyāya:

In S. Phillips and N.S. Tatacharya, Epistemology of Perception (New York: American Institute of Buddhist Studies, 2004), pp. 8-10, it is claimed that in the later Navya-Nyāya (New Logic) tradition of Indian philosophy, not all pramā are generated by pramanna. In this tradition it is not the case that all prama are events of knowing. Nevertheless, in the Buddhist tradition, since no distinction is made between pramā and pramāna, all pramā /pramāna are episodes of knowing. (Stoltz 2007: 401)

In general, Stoltz's position is the following:

[E]pisodes of factive assessment [in Indo-Tibetan epistemology] provide us with no true examples of Gettier cases, and [we should] doubt the more general claim that there are any true analogues of the Gettier problem discussed in the broader Indo-Tibetan epistemological tradition. It is no doubt true that there are examples in the Indian and Tibetan traditions that are similar to Gettier cases in some respects. Yet these examples are not, I contend, similar in any respect that would warrant them to be classified as genuine analogues of the Gettier problem. (Stoltz 2007: 396, emphasis added)

\section{ACE PHILOSOPHYAS ONE KIND OF BI-DIRECTIONAL PUBLIC PHILOSOPHY}

One thing that Stoltz's analysis and argument illustrates is that things can get messy when we get into the details about comparative philosophy. Stoltz carefully navigates several issues while at the same time presenting important insights from which one can learn about cross-cultural epistemology. In connection with his efforts, I would like to draw attention to two important points that show how things can get even more complicated in a way that hopefully leads to a more robust discussion of the issue.

On the one hand, from the perspective of analytic epistemology, an account of what constitutes a Gettier scenario is required for a good argument that leads to the conclusion that a Gettier scenario cannot be found in classical Indian philosophy. That is, an argument of the form G-style cases cannot be found in textual source $\mathrm{T}$ needs to be based on an account of what G-style cases are. It seems clear that there could be different accounts of what constitutes a Gettier scenario. For example, we might distinguish between a broad account and a narrow account. To draw this distinction consider Bertrand Russell's famous clock example. 
Suppose on Saturday, May 29, 2015, Manjula looks at a clock on a wall, that unbeknownst to her, stopped on Friday, May 28, 2015, at exactly 4pm. On the basis of looking at the broken clock she forms the belief that it is $4 \mathrm{pm}$ on Saturday. It is in fact 4pm on Saturday; so she has a true belief that it is 4pm. Question: On the basis of her looking at the watch, does she know that it is $4 \mathrm{pm}$ ? Arguably she does not, since the clock is broken.

Under the broad account of what constitutes a Gettier scenario we can say that Manjula is in a Gettier scenario, since she has a true belief, and arguably she does not know. Under the narrow account we can say that Manjula is not in a Gettier scenario, since it isn't clear that she is justified in believing that it is $4 \mathrm{pm}$. The difference between the two accounts rests on how much attention is given to the question of justification. Typically, a Gettier scenario is a scenario in which one has a justified true belief that is not knowledge, such as in the original example involving the Ford. The narrow account captures this important element. The broad account leaves the question of justification open. Since it isn't clear that Manjula is justified in believing that it is 4pm, it isn't clear that she has a justified true belief, even though it is quite clear that she does not know that it is $4 \mathrm{pm}$. So, whether an example, Buddhist in origin or not, counts as a Gettier scenario, in part, depends on the account one gives of what a Gettier scenario is.

On the other hand, from the perspective of classical Indian philosophy and comparative epistemology, we must be careful to distinguish between the different schools that one can find in the classical Indian tradition, such as The Epistemological School of Buddhism vs. the Abhidharma School of Buddhism, Advaita Vedānta vs. Yoga, Nyāya vs. Navya-Nyāya, and of course Mīmāṃsā vs. Sāṃkhya. Clearly, we should be careful not to argue as follows: since tradition $\mathrm{T}$ of classical Indian philosophy only offers a superficially similar Gettier scenario, it is likely that the other traditions also offer only a superficially similar Gettier scenario. Classical Indian philosophy can be as nuanced and detailed as the finest debates one finds in analytic epistemology. We may find that while Buddhists of one period of time have one account of pramāna, thinkers in the Advaita Vedānta tradition or Nyāya tradition at another period of time have another account of pramāna. ${ }^{3}$

In my view, these points lead to a constructive account of what Stoltz's investigation in comparative philosophy can be taken to suggest in connection with the work of experimental philosophy. That constructive point is simply the following: thinking about theoretical issues across philosophical traditions in conjunction with experimental philosophy and analytical reasoning creates a narrative that enriches, informs, and critically engages the public. In light of this fact, let me propose a view about how analytic philosophy, experimental philosophy, and comparative

\footnotetext{
${ }^{3}$ I would like to thank Jonathan Stoltz for extended commentary on my presentation of his account as well as the difference between broad and narrow readings of the Gettier scenario. I would also like to credit my interest in investigating the issue of whether Gettier scenarios can be found in classical Indian philosophy to an exchange between Edouard Machery, Jennifer Nagel, Jonathan Weinberg, and Julien Dutant about how best to understand Stoltz's paper and the broad and narrow readings of what constitutes a Gettier case.
} 
philosophy might work together to make for a good kind of public philosophy, a kind that mixes elements of the philosophy-to-public direction of fit with the public-tophilosophy direction of fit. Let ' $\mathrm{A}$ ' stand for analytic conceptual analysis, ' $\mathrm{C}$ ' for historical comparative analysis, and ' $\mathrm{E}$ ' for experimental analysis. Consider, yet another triangle, one that describes the relation between these three areas of investigation.

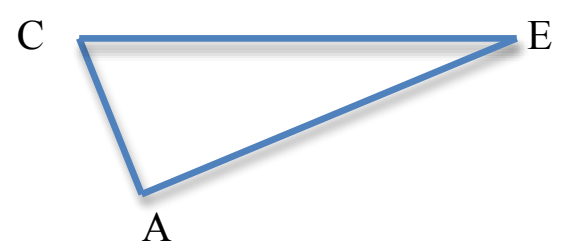

Recognizing that the pure analysis of concepts is important in a specific sense can help build a great harmony in philosophy across these areas. The analysis of concepts needs to be seen as being done, not for the purpose of finding out the truth about concepts, but rather for the purpose of clarifying and formulating inquiry in a better way. For example, in order to test whether there is variation between Europeans and Asians over the role of justification in knowledge, we need to first control for another component of knowledge outside of justification. That is, we need to choose a conception of knowledge that includes justification, but also includes other features. And importantly, different conceptions of knowledge can include justification yet vary over another component. For example, take note of the fact that there are both (i) infallibilist and (ii) fallibilist conceptions of knowledge.

(i) $\square[\mathrm{K} p \rightarrow p]$, necessarily, If $x$ knows that $p$, then $p$ is true.

(ii) $\diamond[\mathrm{K} p \wedge \neg p]$, it is possible for $x$ to know that $p$, and yet $p$ is false.

If we want to test to see whether there is variation of intuitions on

(iii) $[\mathrm{K} p \rightarrow \mathrm{JB} p]$, If $x$ knows that $p$, then $x$ is justified in believing that $p$.

we have to pick a conception of knowledge.

Supposedly, a study might want to show that Europeans and Asians share an infallibilist conception of knowledge captured by (i), and disagree over justification captured in (iii). If the results showed that Asians hold (ii), but Europeans hold (i), and they disagree over (iii) we would be in a situation in which the two groups have different intuitions. ${ }^{4}$ But more importantly, we would be in a situation in which we ought to say: the two groups don't share a common conception of knowledge. Thus the question arises: how do we pick what conceptual connections we should hold to

\footnotetext{
${ }^{4}$ See Vaidya (2012) for a more robust discussion of this point with respect to experimental inquiry about variation in intuition.
} 
for the purpose of cross-cultural empirical investigation? There is no way to do this other than by engaging in analytical inquiry and conceptual analysis. But there is no way to do this responsibly without doing it in a historically informed cross-cultural way. That is, had we looked at the history of classical Indian philosophy for information and inspiration, in addition to cross-cultural psychological studies of the sort done by Richard Nisbett, the initial inquiry into intuition variation concerning knowledge might have engaged a wider battery of questions about cross-cultural intuition that reveal important insights in cross-cultural epistemology. ${ }^{5}$

More importantly, by putting together Analytical philosophy, Comparative philosophy, and Experimental, or Empirically-Engaged, philosophy we are in a better position to do public philosophy that employs a wider set of tools from what we find in any of these kinds of philosophical methods taken alone. What we have is, ACE philosophy, where 'analytical' means nothing more than analysis by reflection on cases, 'comparative' means historically informed cross-cultural and cross-traditional investigation, and 'experimental or empirically-engaged' refers either to: (i) running some kind of study on a population that uses an effective instrument, not necessarily surveys; or (ii) engaging empirical work, such as what we find in cognitive science, anthropology, psychology, or linguistics.

I think that ACE philosophy is one kind of bidirectional public philosophy, although it is not the only kind, nor perhaps even the most interesting kind. It has the philosophy-to-public direction of fit because it requires training in traditional philosophy in order to engage in it. One needs to know what philosophers in various traditions have said, and one needs to know how to deploy these theories for the purposes of creating novel and interesting hypotheses. In addition, it is journalistic and enrichment-based because it aims to reveal to the public that questions in and about the human condition have a variety of answers from different cultures. And the presentation of an investigation that has the ACE structure is simply more engaging. That is, as a testable hypothesis, I think the public would find the first piece less interesting than the second piece.

A study of potential variation in judgment across western folk and Indian folk on knowledge attribution in a Gettier case

A study of potential variation in judgment across western folk and Indian folk on knowledge attribution in a Gettier case with a backstory of comparative epistemology

More importantly, though, ACE has elements of the public-to-philosophy direction of fit for two reasons. First, ACE requires that the public be included in the conversation for philosophy to be done. There are two ways in which this holds. On the non-academic side, there is engagement with the public directly. For example, in experimental philosophy, one must engage folk judgments about scenarios alongside

\footnotetext{
${ }^{5}$ See Nisbett (2004) for examples of cross-cultural psychology studies in which we find differences between Asian and Western styles of thinking.
} 
theoretical analyses in order to get at a meaningful philosophical engagement about knowledge, consciousness, or justice. On the academic side, there is engagement with other disciplines that do not fall under the narrow definition of philosophy, such as cognitive neuroscience, linguistics, or anthropology. Second, by paying attention to other cultures and traditions, we may generate new questions. For example, for the past fifteen years, experimental philosophy has explored folk judgments about cases by asking non-western folks about questions from the western canon, such as the Gettier case. However, there are lots of ideas and questions that we could ask western folks about through engagement with non-western philosophy.

For example, one kind of ACE philosophy is found in the work of Evan Thompson's wonderful article "Dreamless Sleep, the Embodied Mind, and Consciousness: the Relevance of a Classical Indian Debate to Cognitive Science." In this article he argues that:

The philosophical schools of Advaita Vedānta and Yoga maintained that consciousness is present in dreamless sleep, whereas the Nyāya School maintained that it is absent. Consideration of this debate, especially the reasoning used by Advaita Vedānta to rebut the Nyāya view, calls into question the standard neuroscientific way of operationally defining consciousness as "that which disappears in dreamless sleep and reappears when we wake up or dream." The Indian debate also offers new resources for contemporary philosophy of mind. At the same time, findings from cognitive neuroscience have important implications for Indian debates about cognition during sleep, as well as for Indian and Western philosophical discussions of the self and its relationship to the body. Finally, considerations about sleep drawn from the Indian materials suggest that we need a more refined taxonomy of sleep states than that which sleep science currently employs, and that contemplative methods of mind training are relevant for advancing the neurophenomenology of sleep and consciousness. (Thompson 2015: 1)

Thompson's work, in my view, is clearly one kind of ACE philosophy. On this kind $\mathbf{E}$ stands not so much for survey-based experimental philosophy. Rather it stands for the Empirically-Engaged kind, which is informed by Analytical thinking as well as Cross-cultural and cross-traditional philosophy.

Finally, by attending to cultures and traditions outside of western philosophy, ACE brings ideas and arguments into play that may have the ability to bring about a more diverse body of philosophers because the ideas are now being taken from different cultures and traditions where perhaps everyone can identify with the contributors as well as feel good about the diverse cultural contributions that are part of our joint inquiry into the human condition. It is important to keep in mind that public philosophy that is bidirectional has an epistemic dimension that pertains to knowledge building. If our goal as philosophers is to produce an account of justice, knowledge, or beauty, it might be important for us to engage in two kinds of counterbiasing activities. On the one hand, we might need to make sure that our thought about justice, knowledge, and beauty does not float free from how those that are not 
trained in philosophy think and engage with justice, knowledge, and beauty. To this end, the non-philosophical academic and non-academic public plays an anchoring role on our theorizing. On the other hand, "we" might need to be more inclusive, so that our engagement with justice, knowledge, and beauty takes into account potentially different points of view.

\section{ACKNOWLEDGEMENTS}

I would like to thank Stephen Stich and Edouard Machery for inviting me to participate in the 2015 Philosophy Meets Cultural Diversity Conference at the Center for Philosophy of Science at the University of Pittsburgh. Many of the ideas for pursuing this project were solidified during that conference. Thanks to Stephen Phillips, Nirmalya Guha, and J. L. Shaw for discussion of issues in classical Indian philosophy. Thanks to Rita Manning and Janet Stemwedel for extensive comments on this paper that led to a much-improved rendering of my ideas. Thanks to Purushottama Bilimoria and Bo Mou for encouraging me to think more about the past and future of comparative philosophy.

\section{REFERENCES}

Bratton. B. (2015), “Outing A.I.: Beyond the Turing Test,” The Stone, New York Times $<$ http://opinionator.blogs.nytimes.com/2015/02/23/outing-a-i-beyond- theturing-test $/>$.

Davis, A. (2003), Are Prisons Obsolete? (Seven Stories Press).

Ganeri, J. (2014), The Lost Age of Reason: Philosophy in Early Modern India 14001750 (The Oxford History of Philosophy Series) (Oxford University Press).

Gettier, E. (1963), "Is Justified True Belief Knowledge," Analysis, 23: 121-123.

Gopnik, A. (2013), "On Hume and Buddhism” Philosophy Bites hosted by D.

Edmonds and N. Warburton. Available at: <http://philosophybites.com/2013/09/ alison-gopnik-on-hume-and-buddhism.html $>$

Kim, M. \& Yuan, Y. (2001, u.p.s.), "No Cross-Cultural Differences in Gettier Car Case Intuition: A Replication Study of Weinberg et al. 2001" $<$ http://philpapers.org /archive /KIMNCD.pdf $>$

Marshall, R. (2013), "Forgiveness, Blame, Reasons...," interview with Pamela Heironymi, 3A.M. Magazine $<$ http://www.3ammagazine.com/3am/forgivenessblame-reasons/ $>$.

Mou, Bo (2010), "On Constructive-Engagement Strategy of Comparative Philosophy," Comparative Philosophy 1.1: 1-32<http://www.comparative philosophy.org>.

Nagel, J. San Juan, V. \& Mar, R. (2013), "Lay Denial of Knowledge for Justified True Beliefs," Cognition, 129: 652-611.

Nisbett, R. (2004), The Geography of Thought: How Asians and Westerners Think 
Differently... and Why (reprint edition) (Free Press).

Philips, S. \& Tatacharya, R. (2004), Epistemology of Perception: Gangeśa's Tattvacintamani Jewel of Reflection on the Truth (About Epistemology): The Perception Chapter (Pratyakșa-Khaṇda), Transliterated Text, Translation, And Philosophical Commentary, Treasury of the Indic Sciences (New York: American Institute of Buddhist Studies).

Priest, G. (2015), "Beyond True and False," Aeon Magazine. <http://aeon.co/ magazine/philosophy/logic-of-buddhist-philosophy>.

Potter, K. (1984), “Does Indian Epistemology Concern Justified True Belief?” Journal of Indian Philosophy, 12: 307-327.

Sandel, M. (2006), Public Philosophy: Essays on Morality in Politics (Harvard University Press).

Sandel, M. (2010), Justice: What's the Right Thing to Do? (Farrar, Straus, and Giroux).

Shaw, J. L. (2015a, u.p.s.), "Knowledge, Belief, and Doubt: Some Contemporary Problems and their Solutions from the Nyāya Perspective".

Shaw, J. L. (2015b, u.p.s.), "Sources of Knowledge: Perception, Inference, and Testimony: Some Contemporary Problems and their Solutions from the Indian Perspective."

Shiva, V. (2002), Water Wars: Privatization, Pollution, and Profit (South End Press).

Singer, P. (2007), The Ethics of What We Eat: Why Our Food Choices Matter (Rodale Publishing).

Stoltz, J. (2007), "Gettier and Factivity in Indo-Tibetan Epistemology," Philosophical Quarterly 57 (228): 394-415.

Thompson, E. (2015), "Dreamless Sleep, the Embodied Mind, and Consciousness: the Relevance of a Classical Indian Debate to Cognitive Science," $<$ http://openmind. net/papers/dreamless-sleep-the-embodied-mind-and-consciousness-therelevance-of-a-classical-indian-debate-to-cognitive-science $>$.

Weinberg, J., Nichols, S. \& Stitch, S. (2001), "Normativity and Epistemic Intuitions," Philosophical Topics, 29: 429-460.

Williamson, T. (2012), "Logic and Neutrality," The Stone, New York Times $<\mathrm{http}: / /$ opinionator.blogs.nytimes.com/2012/05/13/logic-and-neutrality/>.

Vaidya, A. (2012), “Intuition and Inquiry,” Essays in Philosophy, 13.1: 284-295.

Yancy, G. (2015), "Molefi Kete Asante: Why Afrocentricity?" The Stone, New York Times $<$ http://opinionator.blogs.nytimes.com/author/george-yancy/?_r=0 $>$. 